\begin{tabular}{lllllllllllllllllllllllllllllllll}
\hline$R$ & $E$ & $V$ & I & S & T & A & D & E & E & S & T & U & D & I & O & S & I & N & T & E & R & N & A & C & I & O & N & A & L & E & S
\end{tabular}

\title{
Derecho internacional y sociedad global: ¿ha cambiado la naturaleza del orden jurídico internacional?
}

\author{
Francisco Orrego Vicuña
}

\begin{abstract}
El derecho internacional moderno ha iniciado el quinto siglo de su evolución, caracterizada ésta por una constante transformación del contenido y las modalidades del orden jurídico. La sociedad internacional que hoy conocemos, y la que podemos percibir hacia el futuro, también es muy diferente de aquella que caracterizó a la Europa del siglo diecisiete y de las transformaciones que tuvieron lugar hasta el siglo veinte inclusive. Estamos, a no dudarlo, ante una sociedad global. La pregunta que permanece, sin embargo, es si acaso la naturaleza del orden jurídico internacional que rige esa sociedad ha cambiado de manera fundamental o bien si acaso estamos frente a un proceso de transformación gradual dentro de ciertos principios que en lo sustancial permanecen inalterados ${ }^{1}$. Es el tema de los límites y oportunidades que el derecho internacional encuentra en la sociedad global.
\end{abstract}

${ }^{1}$ Prosper Weil: Le droit international en quête de son identité, Cours Général de Droit International Public, Académie de Droit International, Vol. 237, 1992-VI, 13-369, p. 26, con especial referencia a Bourquin y Fitzmaurice. Véase también René-Jean Dupuy: "La codification du droit international à-telle encore un interet à l' aube du troisième millenaire?", en Le Droit International a l' heure de sa codification, Etudes en l' honneur de Roberto Ago, 1987, 261-271; p. 261. 
TRADICIÓN Y CAMBIO EN LA SOCIEDAD INTERNACIONAL

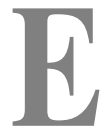

1 punto de partida para responder a esta interrogante es evidentemente el de precisar las características de la sociedad internacional tradicional. Hedley Bull identificó cinco características principales de lo que llamó la sociedad Grociana ${ }^{2}$, esto es, la visión tradicional de la sociedad internacional. Estas características fueron la del papel central del derecho natural; la universalidad de la sociedad internacional; el papel de los individuos en esa sociedad; la aplicación del derecho mediante la solidaridad y la ausencia de instituciones internacionales ${ }^{3}$.

$\mathrm{Si}$ esas características se contrastan con las de la actual sociedad internacional se pueden apreciar muchos cambios. Con todo, más allá de las formas, se plantea la interrogante indicada de si acaso los principios esenciales en que descansa esta sociedad siguen siendo los mismos, aún cuando expresados en un nuevo contexto y de manera también diferente.

Los cambios de cada período histórico, como su influencia en la naturaleza del derecho internacional, siempre han sido una materia que ha llamado la aten- ción de la doctrina del derecho internacional y crecientemente de los estudiosos de las relaciones internacionales ${ }^{4}$. Grandes hitos, como el de la Paz de Westfalia, la Segunda Guerra Mundial o el término de la Guerra Fría, han determinado, a no dudarlo, cambios significativos en la sociedad internacional. La influencia específica de estos cambios en la naturaleza de la sociedad y del ordenamiento jurídico ha sido, sin embargo, materia de apreciaciones opuestas.

\section{El concepto de gobierno mundial sería una utopía, al igual que muchas expresiones de idealismo frustradas por el curso de la historia.}

Para un sector de la doctrina del derecho y las relaciones internacionales, los cambios ocurridos son de tal magnitud que el propio Estado soberano ha sido superado y está en vías de extinción en el marco de una sociedad global. Teorías atractivas, pero muy debatibles, como la ausencia de guerra entre las democracias en este nuevo marco ${ }^{5}$, la obsolescencia del conflicto $^{6}$, el choque de las civilizaciones ${ }^{7}$

\footnotetext{
${ }^{2}$ Hedley Bull, Benedict Kingsbury y Adam Roberts (eds.), Hugo Grotius and International Relations, 1992.

${ }^{3}$ Hedley Bull, "The importance of Grotius in the study of international relations", en op. cit., supra nota 2, 65-93; pp. 78-91.

${ }^{4}$ Philip Allott, Eunomia. New Order for a New World, 1990.

${ }^{5}$ Dean V. Babst, “A force for peace”, Industrial Research, Vol. 14, 1972, 55-58; R. J. Rummel, "Libertarianism and international violence", Journal of Conflict Resolution, Vol. 27, 1983, pp. 27-71; Bruce Russett, "The politics of an alternative security system: toward a more democratic and therefore more peaceful world”, en Burns Weston (ed.), Alternatives to nuclear deterrence, 1989.

${ }^{6}$ John Mueller, Retreat from doomsday: the obsolescence of major war, 1989.

${ }^{7}$ Samuel P. Huntington, The Clash of Civilizations and the Remaking of World Order, 1996.
} 
o el fin de la historia ${ }^{8}$, combinadas con estudios sobre el nacimiento y caída de las grandes potencias ${ }^{9} \mathrm{y}$ el colapso de los imperios ${ }^{10}$, revelan la amplitud de esos cambios para quienes así piensan.

Otro sector de la doctrina, sin embargo, tiene una visión diferente ${ }^{11}$. El concepto de un gobierno mundial o sus variables no sería más que una utopía, como antes lo fueron el proyecto de paz perpetua y otras muchas expresiones de idealismo que se vieron frustradas por el curso de la historia. El futuro no estaría exento, en este punto de vista, de guerras, conflictos, ideologías o imperios, ni mucho menos se acercaría la sociedad internacional al fin de la historia.

\section{EVOLUCIÓN SIN RUPTURA DEL DERECHO} INTERNACIONAL

Las consecuencias de estas apreciaciones para el orden jurídico internacional son también diferentes. Hay quienes piensan que el propio derecho internacional, por su naturaleza histórica interestatal, sería hoy, o en el futuro cercano, una obsolescencia comparable a la del propio Estado $^{12}$. Estaríamos, en cambio, frente a un derecho global que no reconoce límites territoriales o conceptuales. El con- cepto de derecho mundial vendría así a reemplazar al de derecho internacional.

Pero también hay quienes piensan, con buena razón, que estamos frente a una realidad usual asociada a la evolución natural de toda sociedad y que se refleja, por consiguiente, en el ordenamiento jurídico que la rige ${ }^{13}$. Es la siempre presente necesidad de toda sociedad de compatibilizar la estabilidad de sus estructuras con las presiones del cambio.

\section{El concepto de derecho mundial vendría a reemplazar el de derecho internacional.}

Si se examinan las características fundamentales de la sociedad internacional tradicional, indicadas anteriormente, a la luz de las realidades actuales, se podrá observar que hay un profundo cambio, pero inserto en una relación de continuidad que es todavía más significativa.

Un buen número de los desarrollos más importantes que han tenido lugar en el derecho internacional se inspiran en la necesidad de asegurar la libertad del hombre, sus derechos, dignidad y bienestar ${ }^{14}$. Independientemente de que esta realidad se fundamente en una visión del derecho natural o en una expresión masiva del

\footnotetext{
${ }^{8}$ Francis Fukuyama, “The end of history?", The National Interest, No. 16, Summer 1989, pp. 3-18.

${ }^{9}$ Paul Kennedy, The rise and fall of great powers, 1987.

${ }^{10}$ Hugh Trevor-Roper y George Urban, "Aftermaths of Empire. The lessons of upheavals and destabilisation", Encounter, diciembre de 1989, pp. 3-16.

${ }^{11}$ F. H. Hinsley, Power and the Pursuit of Peace, 1963.

12 Jacques Chevallier, "Mondialisation du Droit ou Droit de la Mondialisation?", Université de Geneve, Colloque sur la Mondialisation du Droit, Sion, 22-24 junio de 2000.

${ }^{13}$ Shabtai Rosenne, The Perplexities of Modern International Law, 2002, pp. 38-46.

${ }^{14}$ J. Stone, Human Law and Human Justice, 1965.
} 
derecho positivo, el hecho concreto es que el derecho internacional de ayer y de hoy está vinculado a la esencia de la comunidad humana como beneficiaria de sus normas. Ello puede olvidarse en algunos momentos históricos en que el Estado aparece como el único motivo de preocupación, pero esa esencia humanitaria no tarda en reaparecer. La continuidad es entonces permanente.

Esta misma esencia es la que condiciona los cambios ocurridos respecto de los actores del sistema internacional y, como consecuencia, de los sujetos del derecho internacional que participan en ese sistema ${ }^{15}$. El papel exclusivo que ocupó el Estado como actor y sujeto ha sido reemplazado por otra dimensión. En ella el Estado es todavía predominante, pero comparte sus funciones con las organizaciones internacionales y otras entidades.

\section{El Estado comparte sus funciones con las organizaciones internacionales y otras entidades.}

Probablemente esta realidad debió encontrarse siempre presente, pues en su propio origen el Estado no fue más que una concepción intelectual destinada a defender al individuo de los abusos a que había conducido el fraccionamiento extremo del poder político. Sin embargo, ello, en algún período, más bien largo, fue olvidado y pasó el Estado a adquirir una supremacía y un poder omnímodo que le permitieron abusar de la propia comunidad humana que debía defender.

Para corregir esta distorsión es que la comunidad internacional construyó gradualmente sistemas de cooperación y de organización internacional. Pero más importante aún fue el hecho de que el propio individuo, tanto en su condición de persona natural como de su agrupación en diferentes entidades jurídicas, inició una participación directa como actor del sistema y sujeto del derecho internacional. Si bien esta participación está todavía circunscrita a ciertas materias y ámbitos, ha llegado a constituir una de las características centrales de la actual sociedad internacional. Además, ciertamente se trata de una tendencia que habrá de continuar. De esta manera, el derecho internacional reencuentra lo que fue su motivación original.

No deja de ser una paradoja que las propias estructuras diseñadas para controlar el poder absoluto del Estado han ocasionalmente incurrido también en formas de acción incompatibles con su función. La crítica que hoy afecta a algunas organizaciones internacionales que han buscado atender a su propio interés por sobre aquel de los supuestos destinatarios o beneficiarios de su cometido, es indicativa de que la comunidad internacional busca hoy otras formas de entendimiento y regulación.

Tampoco está el desempeño del individuo como actor exento de críticas, por la misma razón de que ocasionalmente

${ }^{15}$ Societé Française pour le Droit International, L' État souverain à l' aube du XXIe siècle, Colloque de Nancy, 1994. 
también algunas organizaciones que los agrupan han incurrido en abusos o exageraciones. En el hecho, algunas organizaciones han buscado competir con el papel de otros actores del sistema y sustituir sus funciones. Esta pretensión ha motivado una reacción destinada a establecer límites y modalidades claras de participación del individuo en el sistema.

La exigencia de una mayor transparencia y profesionalismo en el desempeño, así como la sujeción a órganos de control, son algunas de las condiciones de participación que comienzan a discutirse. Mientras ellas no se logren es la propia participación del individuo la que resulta limitada. Ello también es demostrativo de que la comunidad internacional busca otras modalidades de entendimiento y regulación.

\section{UN DERECHO UNIVERSAL Y MULTICULTURAL}

Este conjunto de características es el que también ha llevado a una sociedad internacional multicultural ${ }^{16}$, en que son muchas las culturas que intervienen en la elaboración del derecho que la rige. La orientación histórica eurocéntrica que tuvo el derecho internacional en sus orígenes ha sido reemplazada por una visión más amplia en que otras naciones y regiones contribuyen con sus propias pers- pectivas. El derecho internacional ya no es el monopolio de una determinada cultura y su manera de apreciar la sociedad. De ahí es que ya no resulta posible imponer una visión jurídica o política que no sea compartida por el conjunto de la sociedad internacional o al menos por algunos de sus actores más significativos.

\section{La orientación eurocéntrica del derecho internacional se ha reemplazado por una visión más amplia.}

Dos consecuencias han surgido paralelamente de esta visión más amplia y representativa. La primera es que las estructuras regionales han adquirido una vida propia y complementaria de la sociedad global. La "era del regionalismo" es una realidad que no debe pasar desapercibida ${ }^{17}$. En ocasiones es una realidad muy estructurada e institucionalizada, en tanto que en otras expresiones es informal o descentralizada, pero no por ello menos real. La sociedad internacional es siempre de naturaleza universal, pero se apoya en una medida importante en estructuras regionales. La acción internacional centralizada que puede asociarse a la naturaleza de una sociedad global sólo será en realidad posible si descansa en una cooperación regional efectiva.

${ }^{16}$ Edith Brown Weiss, "The new international legal system", en Perspectives on International Law, 1995, 63-82, p. 66; C. G. Weeramantry, "Cultural and Ideological Pluralism in Public International Law”, en Liber Amicorum Judge Shigeru Oda, 2002, 1491.

${ }^{17}$ W. W. Rostow, “The coming age of regionalism. A 'metaphor' for our time?", Encounter, junio de 1990, pp. 3-7. 
La segunda consecuencia es que una sociedad multicultural normalmente llevará a que su estructura de poder sea multicéntrica. Varios centros de poder económico y político normalmente coexistirán en una sociedad global. Si bien en algún período pareciera que sólo un centro es predominante, ese es un fenómeno netamente transitorio pues la sociedad busca equilibrios. Tampoco ello es conceptualmente diferente de lo que fue la Europa de Grocio. Precisamente, el papel del derecho internacional es el de asegurar que las relaciones entre centros competitivos se conduzcan de conformidad con una estructura jurídica aceptada por todos los partícipes del sistema.

SOLIDARIDAD SIN COERCIÓN EN LA ESENCIA DEL DERECHO INTERNACIONAL

La ejecución del derecho internacional, hoy como ayer, descansa fundamentalmente en la solidaridad. Ello es particularmente cierto en materia de seguridad colectiva y del mantenimiento de la paz y la seguridad internacionales. No existe un mecanismo coercitivo independiente de la cooperación entre los Estados, ni siquiera en el marco de las Naciones Unidas. También es poco probable que llegue a existir en una sociedad de las características que se han mencionado.

En materias específicas y más bien de carácter funcional, los Estados han aceptado procedimientos coercitivos más eje- cutivos o autónomos. Ello se aprecia hoy, por ejemplo, en el campo de las inversiones y en menor medida en el campo del comercio. Es probable que este enfoque continúe desarrollándose, en la medida en que la cooperación en esos campos se hace más estrecha, pero no es previsible que alcance a la estructura general del derecho internacional ni menos a aquellos elementos que tienen un alto componente político.

\section{La ejecución del derecho internacional descansa en la solidaridad.}

En apariencia, la vida activa de las organizaciones internacionales contemporáneas podría significar un cambio de importancia respecto de lo que fue una sociedad caracterizada por la ausencia de instituciones internacionales o su función más bien limitada ${ }^{18}$. Sin embargo, es posible observar que tampoco esta característica contemporánea ha logrado alterar la esencia de la sociedad internacional.

La propia actuación de las organizaciones internacionales continúa dependiendo en alta medida del consenso de sus Estados miembros y de otros factores que también estaban presentes en el derecho internacional desde sus orígenes, aun cuando expresados de una manera informal y diferente. Además, en lo sustancial, las organizaciones internacionales son

${ }^{18}$ Louis B. Sohn, "The role of international law in the 21st century", Exposición realizada en la Vrije Universiteit, Brussels, 23 de marzo de 1990; pp. 5-6. 
agentes mediante los cuales los Estados canalizan su cooperación.

De nuevo, lo anterior reconoce excepciones en algunas materias específicas y más bien técnicas, o en la práctica de algunas regiones altamente institucionalizadas, pero no es un fenómeno generalizado en la sociedad internacional. Las decisiones de naturaleza política no forman por cierto parte de esta excepción, pues los Estados desean salvaguardar su autonomía en materias que les son particularmente sensibles.

\section{CONTINUIDAD HISTÓRICA Y RACIONALIDAD DE ESTRUCTURAS}

Las transformaciones de la sociedad internacional son muchas y profundas, pero todas ellas pueden identificarse específicamente con una continuidad histórica que se remonta a los orígenes del derecho internacional. Estas transformaciones continuarán produciéndose, especialmente en la medida en que la revolución tecnológica se incrementa ${ }^{19} \mathrm{y}$ en que la economía global alcanza nuevas expresiones de competitividad y participación $^{20}$. A su vez, esos cambios se mantendrán previsiblemente dentro de una estructura conocida y que en nada disminuye la naturaleza universal del sistema ni del derecho que lo rige. Más bien por el contrario, esas estructuras tradicionales son las que aseguran que el derecho internacional continúe siendo propiamente internacional y expresivo de una amplia participación.

\section{Las transformaciones de la sociedad internacional corresponden a una continuidad histórica.}

La evolución que se ha indicado ha sido enfocada de diferente manera por la doctrina del derecho internacional. En la opinión de distinguidos juristas e instituciones especializadas ${ }^{21}$, los cambios pueden ser muchos pero los conceptos básicos permanecen en esencia inalterados. Este sería particularmente el caso en lo que respecta al papel del consenso en la elaboración del derecho internacional y en la adopción de decisiones por organizaciones y conferencias internacionales.

Dentro de esta perspectiva, Weil ha puesto énfasis en la permanencia del derecho internacional y en el hecho de que éste, a pesar de los componentes multiculturales de la sociedad internacional, se mantiene como un ordenamiento univer$\mathrm{sal}^{22}$. Una consecuencia de lo anterior es la advertencia acerca de la inconveniencia de reducir los estándares para identificar las normas de la costumbre internacional o de tratar de reemplazar el modelo que es

\footnotetext{
${ }^{19}$ Rostow, loc. cit., supra nota 17; p. 3.

${ }^{20}$ Ibid.; p. 3.

${ }^{21}$ American Law Institute, Restatement of the Law. The foreign relations law of the United States, Vol. I, 1987; p. 19, según citado y comentado por Weil, op. cit., supra nota 1, p. 33. Véase también Fritz Münch, "La codification inachevée", en op. cit. (Ago), supra nota 1, pp. 373-385, pp. 376-379.

${ }^{22}$ Weil, op. cit., supra nota 1, pp. 33, 87-88.
} 
propio de la estructura normativa de la sociedad internacional por otro que toma sus características de la sociedad nacional ${ }^{23}$. Cada uno de estos ordenamientos debe mantener su propia identidad y el hecho de que sean mutuamente complementarios no significa que su naturaleza deba fusionarse o confundirse.

\section{Para facilitar la innovación jurídica hay que superar los obstáculos estructurales derivados del derecho internacional tradicional.}

En el punto de vista de otra parte de la doctrina, sin embargo, el problema radica precisamente en cómo superar los obstáculos estructurales que derivan del derecho internacional tradicional, para facilitar así una innovación jurídica que se estima indispensable. En este punto de vista, algunos de esos obstáculos derivan de los límites impuestos por la exigencia del consenso y la necesidad de alcanzar un procedimiento de elaboración del derecho internacional que sea, a la vez, rápido y expedito. El llamado derecho informal (soft law) y otros mecanismos conducentes a la adopción de decisiones responderían a esta exigencia ${ }^{24}$.

Puede apreciarse que las tendencias relativas a la necesidad de asegurar la estabilidad del sistema y del derecho internacional contrastan con otras que buscan cambiar tanto la sociedad como ese ordenamiento. Esta es una disyuntiva permanente en toda sociedad, pero en ocasiones lo que es una discusión legítima de alternativas se transforma en una pugna y confrontación que ciertamente no contribuyen a un progreso gradual y ordenado del derecho internacional.

\section{UNA NUEVA INTEGRACIÓN DEL DERECHO}

Edith Brown Weiss ha explicado acertadamente que esta interacción y acomodo entre diferentes tendencias no resulta muchas veces un proceso fácil, pues la sociedad internacional, que descansaba en gran medida en la independencia y la igualdad soberana de un número limitado de Estados, se ve enfrentada hoy día a una participación significativamente más amplia, que tiende a debilitar las presunciones de la igualdad soberana ${ }^{25}$.

El papel de liderazgo que potencias seleccionadas alcanzan en la elaboración del derecho internacional y en la conducción de la sociedad internacional, contrasta muchas veces con la actitud más bien pasiva de un número extenso de países ${ }^{26}$.

${ }^{23}$ Ibid., pp. 161-179, 203 et seq.

${ }^{24}$ C. M. Chinkin, "The challenge of soft law: development and change in international law", The International and Comparative Law Quarterly, Vol. 38, 1989, pp. 850-866; Geoffrey Palmer, "New ways to make international environmental law", American Journal of International Law, Vol. 86, 1992, pp. 259-283.

${ }^{25}$ Weiss, loc. cit., supra nota 16; pp. 63-66.

${ }^{26}$ Louis B. Sohn, "The shaping of international Law", Georgia Journal of International and Comparative Law, Vol. 8, 1978, pp. 1-25. 
Cuáles son esas potencias es un aspecto que varía en cada período histórico relevante, pero el hecho se repite de manera continuada. La realidad actual del derecho internacional y de la conducción de las organizaciones internacionales no es intrínsecamente diferente de la que ha caracterizado a otros períodos, aun cuando el grado de crítica pueda haberse intensificado. Por otra parte, como se ha indicado, las organizaciones no gubernamentales y los individuos han surgido como actores importantes en la elaboración del derecho internacional y en la conducción de la sociedad internacional, dentro de ciertos límites, todo lo cual igualmente contribuye a hacer más relativo el papel del Estado soberano ${ }^{27}$.

Este fenómeno de transformación es particularmente evidente en algunos campos seleccionados, pero no podría considerarse que se trata de una situación generalizada en la sociedad internacional. El desarrollo de la jurisdicción internacional en materia de protección de los derechos de los individuos, en el campo de la protección de las inversiones o en la solución de conflictos comerciales, es verdaderamente notable, pero no alcanza a muchos otros sectores de la vida social. Es probable que el proceso continúe desarrollándose para incluir nuevos sectores, pero ello sólo se logrará en la medida en que los propios actores del sistema acepten la necesidad de esta evolución. Esta aceptación no obedece a que prevalezcan los factores propios de la confrontación indicada, que es más bien de ca- rácter ideológico, sino a razones de conveniencia práctica o al íntimo convencimiento moral de la sociedad acerca de la justicia y necesidad de un progreso determinado.

\section{La separación entre derecho internacional y derecho interno no es tan aguda como en el pasado.}

Es igualmente importante observar cómo el proceso de acomodo que tiene lugar conduce a la integración del derecho dentro de visiones más complementarias para atender a las realidades sociales subyacentes. Así, por ejemplo, en la medida en que la sociedad internacional se globaliza, el derecho internacional público y el privado se integran de una manera más natural, pues ya no existen las barreras soberanas que hacían que uno y otro fueran esferas separadas ${ }^{28}$. De la misma manera, el derecho internacional y el derecho interno desarrollan vínculos más estrechos y expeditos, pues tampoco la separación entre uno y otro es tan aguda como pudo serlo en el pasado. Todo ello dentro de los límites que emanan de la diferente naturaleza de cada ordenamiento jurídico y de las necesidades de gobernabilidad democrática que se expondrán más adelante.

Roberto Ago observaba que el derecho internacional experimenta una progresión geométrica de importancia, que conduce al surgimiento de nuevos temas en el ámbito del ordenamiento jurídico

\footnotetext{
${ }^{27}$ Weiss, loc. cit., supra nota 16; pp. 67-69.

${ }^{28}$ Ibid., pp. 69-79.
} 
internacional ${ }^{29}$. Esta es, en efecto, una realidad de diaria ocurrencia que exige paralelamente buscar nuevas soluciones que atiendan a esas nuevas perspectivas.

En primer lugar, se aprecia la necesidad de buscar soluciones de naturaleza técnica a lo que se ha denominado "la congestión del orden jurídico internacional”. Muchos instrumentos diferentes tratan en ocasiones de aspectos similares o interrelacionados, llevando a una proliferación innecesaria de normas e interpretaciones y generando mayores costos en el campo de las negociaciones internacionales, la creación de nuevas instituciones y la aplicación del derecho internacional ${ }^{30}$. La racionalización de este proceso aparece así como una necesidad de desarrollado ordenado. Una iniciativa técnica para ayudar a este fin ha sido sugerida en cuanto a la posibilidad de crear una base de datos computarizada del derecho internacional, que en parte ya se encuentra disponible en redes electrónicas sobre determinados temas ${ }^{31}$.

Por otra parte, las funciones codificadoras que tradicionalmente han tenido la Comisión de Derecho Internacional de las Naciones Unidas y otros mecanismos similares, públicos y privados, gubernamentales y académicos, han sido alteradas de manera importante por este nuevo panorama de problemas y desarrollos. Siendo esa función todavía de importancia lo es por necesidad más selectiva, abarcando sólo algunos temas y no el conjunto normativo del derecho internacional como pudo ser en el pasado. Ello ha llevado a pensar en que el propio proceso de codificación del derecho internacional se encuentra en gran medida agotado y ciertamente ha llevado a evaluar su funcionamiento ${ }^{32}$.

\section{El fenómeno regional ha tenido más fuerza que el proceso de elaboración de normas universales.}

Estas limitaciones de la codificación tradicional se ven agudizadas por el carácter técnico y especializado que muchos de los nuevos temas del derecho internacional tienen desde su origen, así como por la proliferación de organismos que intervienen en la elaboración de este derecho $^{33}$. En algún momento, la codificación paralela entre organismos de Naciones Unidas y aquellos propios de los sistemas regionales, como fue el caso del sistema interamericano, planteó también problemas de duplicación y compatibilidad, pero este fenómeno, en alguna me-

\footnotetext{
${ }^{29}$ Roberto Ago, "Some new thoughts on the codification of international law", en op. cit., supra nota 1, 35-61; p. 52.

${ }^{30}$ Weiss, loc. cit., supra nota 16; pp. 80-81.

${ }^{31}$ Ibid.; p. 81.

${ }^{32}$ Allott, op. cit., supra nota 4; p. 316; R. P. Dhokalia, "Reflections on International Law-making and its progressive development in the contemporary era of transition", en R. S. Pathak y R. P. Dhokalia (eds.), International Law in Transition, Essays in Memory of Judge Nagendra Singh, 1992; pp. 203-229.

33 "Informe de la Comisión de Derecho Internacional a la Asamblea General sobre la labor realizada en su $48^{\circ}$ período de sesiones, 6 de mayo al 26 de julio de 1996, GAOR, 51st Session, Supplement No 10 (A/51/10), pp. 206-207.
} 
dida, ha sido superado por el hecho de que llegó a prevalecer la función universal por sobre la regional. Con todo, en algunas situaciones, como aquellas que son propias de la Comunidad Económica Europea, el fenómeno regional ha tenido más fuerza que el propio proceso de elaboración de normas universales en ciertos temas.

\section{UNA ORDENACIÓN JERÁRQUICA EN} FUNCIÓN DE PRINCIPIOS BÁSICOS

La esencia del problema, sin embargo, no es de naturaleza técnica sino sustantiva, principalmente en cuanto concierne a la ordenación jerárquica del derecho internacional. Así como el derecho internacional ha experimentado una notable expansión en un sentido horizontal, abarcando cada día más campos de acción, ha habido también un esfuerzo destinado a asegurar una ordenación jerárquica de su estructura. Pero, como se verá, este esfuerzo ha tenido más un carácter académico que práctico o real y en algunas expresiones ha sido excesivo, lo que lejos de contribuir al desarrollo del derecho internacional ha llegado a constituirse en un verdadero obstáculo.

Wolfgang Friedmann había observado hace ya tiempo que el derecho internacional había pasado de una etapa de coordinación de conductas entre los Estados a otra caracterizada por la cooperación, elemento este último que significa una concurrencia más activa de voluntades en el logro de objetivos comunes ${ }^{34}$.
Ello puede efectivamente apreciarse de una manera objetiva en el actual ordenamiento internacional, no tanto en aspectos que tienen un alto componente político, donde muchas veces la cooperación es más nominal que real, pero sí en aspectos de contenido más bien técnico y económico.

\section{El derecho internacional siempre ha admitido la existencia de normas jerárquicamente superiores.}

A su vez, señalaba ese autor que la cooperación venía abriendo paso a una relación de subordinación, en la que el derecho internacional impone a sus sujetos un comportamiento determinado, acercándose así a un ordenamiento estructurado jerárquicamente. Es indudable que el derecho internacional, independientemente de sus manifestaciones en el plano del derecho positivo, siempre ha admitido la existencia de normas jerárquicamente superiores. Ello pertenece a la esencia de todo sistema jurídico, nacional e internacional, que encuentra su fundamento en valores religiosos, ya sea el cristianismo o el islamismo, entre muchos otros.

Existe una expresión clara del derecho natural en este campo, que recoge valores superiores y que siempre culminan en manifestaciones del derecho positivo. La necesidad de salvaguardar los derechos de la persona humana es, probablemente, el más típico de estos valores, por largo tiempo consagrados en la

\footnotetext{
${ }^{34}$ Wolfgang Friedmann, The Changing Structure of International Law, 1964.
} 
doctrina teológica y finalmente reflejados en un amplio sistema del derecho internacional contemporáneo.

\section{La aplicación de normas de superior jerarquía debe ser estricta y objetiva.}

La existencia de normas de jus cogens, que no admiten acuerdo en contrario, o de obligaciones erga omnes, que tienen un alcance universal, es sin duda correcto desde un punto de vista histórico y conceptual. Pero el problema no radica en el concepto sino en su aplicación. Esfuerzos destinados a calificar como normas de esta naturaleza a muchas que los autores o los gobiernos han considerado ideológica o políticamente convenientes, han culminado en una exageración de tal magnitud que ha convertido ese marco conceptual en uno de dudosa reputación.

Iniciativas como la emprendida por la Comisión de Derecho Internacional de las Naciones Unidas para concebir la existencia de crímenes internacionales asociados a la responsabilidad por violación de normas de fundamental importancia en el derecho internacional, a diferencia de los llamados delitos internacionales, que se asociarían a la violación de normas de menor jerarquía, debieron en definitiva ser abandonadas. Ellas no representaban una realidad de la sociedad internacional ni respondían a la estructura de su sistema jurídico, menos aún cuando en la ejemplificación de esos crímenes se agregaban cada día más situaciones antojadizas. Otro tanto es lo que ha ocurrido con la definición de algunos delitos en la esfera del derecho penal internacional y otras iniciativas que parecen no tener más límites que los de la imaginación.

El concepto de la existencia de normas de superior jerarquía debe por cierto salvaguardarse, pero su aplicación debe realizarse de una manera muy estricta y objetiva, fundamentada en lo que la comunidad internacional realmente desea alcanzar dentro de un marco de valores superiores.

Esta relación jerárquica se encuentra evidentemente más desarrollada en el derecho que rige en el ámbito de algunas organizaciones regionales, como es particularmente el caso de la Comunidad Europea, en que los tratados constitutivos han permitido la elaboración y aplicación de un derecho derivado que puede aplicarse directamente en el ámbito nacional o bien asegura su cumplimiento por parte de los Estados miembros y los órganos que administran el sistema comunitario. Pero aun en este contexto, como se observará, existen límites que los Estados miembros están dispuestos a salvaguardar.

\section{LA BÚSQUEDA DE UN ORDENAMIENTO CONSTITUCIONAL}

La evolución ordenada del derecho internacional requiere entonces, como tarea primordial, que se identifiquen en primer lugar los principios básicos en que ese orden descansa. La sociedad internacional todavía se encuentra muy distante de contar con normas que pudieran identificarse como pertenecientes a una jerar- 
quía constitucional. Algunos principios esenciales del derecho internacional pueden asimilarse a esta función constitucional y, en esa medida, adquirir una jerarquía cercana a la del jus cogens, aun cuando serán siempre modificables.

La Carta de las Naciones Unidas ha desempeñado una función constitucional limitada en relación con la prohibición del uso de la fuerza ${ }^{35}$. Igualmente lo han hecho algunas convenciones principales en el campo de la protección de los derechos del individuo, el derecho del mar y algunos otros. Por cierto, esta evolución marca una diferencia importante entre el derecho internacional tradicional y el contemporáneo, pero es una dimensión más selectiva de lo que muchas veces se piensa. Algunas importantes obras doctrinarias han contribuido a la elaboración de estos principios, pero tampoco es éste un fenómeno generalizado ${ }^{36}$.

El perfeccionamiento de estos principios es todavía una tarea pendiente. La Comisión de Derecho Internacional en algunos casos de codificación, como la Corte Internacional de Justicia en algunas sentencias, ha realizado una contribución de interés. Debe también señalarse que en otros casos las conclusiones alcanzadas por estos y otros órganos han distado mucho de poder representar principios genuinos del derecho internacional.

La identificación de estos principios requiere de un examen sistemático de la práctica estatal y de la legislación internacional, la definición de su contenido y alcance y las precisiones del caso mediante comentarios detallados ${ }^{37}$. Todo ello dentro de un enfoque que sea de gran calidad profesional, pues hay ejercicios de identificación de principios que han descansado erróneamente en criterios de mera conveniencia política circunstancial y que en nada han contribuido a la consolidación del derecho internacional.

\section{La identificación de los principios ha solido descansar en criterios de conveniencia política.}

La necesidad de una normativa de jerarquía constitucional en la sociedad internacional no puede ya ignorarse. Las discusiones habidas sobre los poderes del Consejo de Seguridad o sobre los alcances de la legítima defensa, por ejemplo, son claramente indicativas de esta necesidad. Mientras no se elaboren esas normas con la necesaria precisión, se sucederán interminables discusiones gubernamentales y académicas cada vez que tiene lugar una crisis internacional.

Algunas iniciativas destinadas a reconocer una función de revisión judicial a la Corte Internacional de Justicia en re-

${ }^{35}$ Sohn, loc. cit., supra nota 26; p. 13.

${ }^{36}$ Ian Brownlie, Principles of Public International Law, 1990; Oppenheim's International Law, 1992.

${ }^{37}$ American Law Institute, op. cit., supra nota 21. Para una proposición destinada a elaborar una recopilación sistemática y comentada del derecho internacional, véase Louis B. Sohn, "Making international law more user-friendly", Exposición realizada en el Congreso de las Naciones Unidas sobre Derecho Internacional Público, New York, March 17, 1995, según citado por Weiss, loc. cit., supra nota 16 ; p. 81 , nota 50. 
lación con las competencias de los órganos de Naciones Unidas, como la proposición de establecer una Corte Constitucional Internacional, son todas manifestaciones de cómo la comunidad internacional busca identificar las normas básicas de superior jerarquía ${ }^{38}$.

Philip Allott ha escrito con propiedad que "los principios genéricos de una constitución son aquellos principios operativos que hacen posible el progreso social dentro de la sociedad" 39 . En este contexto, el mismo autor ha identificado como normas esenciales aquellas que se refieren a la integración del derecho, delegación de poderes, límites intrínsecos del poder, supremacía del derecho, supremacía del interés social y responsabilidad social ${ }^{40}$.

\section{La búsqueda de los principios} y su precisión ha sido tarea de todos los tiempos.

La evolución del derecho internacional se orienta sin duda hacia el establecimiento de funciones constitucionales que permitan satisfacer la necesidad de contar con principios claros, que sirvan de fundamento al derecho internacional y a la estructura social. Esta inquietud, sin embargo, está presente en el derecho internacional desde sus inicios. La manera de proceder a la identificación de tales principios puede variar de una época a otra, como en la realidad ha ocurrido, pero la búsqueda de los principios y su precisión ha sido una tarea de todos los tiempos.

\section{NATURALEZA PROPIA E INVARIABLE DEL DERECHO INTERNACIONAL}

Los cambios en el derecho internacional han sido sin duda muchos, lo que lleva inevitablemente a la pregunta de si acaso este ordenamiento jurídico ha cambiado o estaría cambiando su estructura y dimensiones cualitativas. ¿Es hoy día el sistema normativo del derecho internacional comparable al del derecho interno, o al menos al de un derecho federal, que descansa en una gestación y ejecución similar a la de los derechos nacionales? ¿O se trata todavía de un derecho que obedece a la particular realidad de las relaciones internacionales entre Estados y otros sujetos, que descansa en la cooperación entre esos sujetos para su elaboración y aplicación $?^{41}$.

El examen de la realidad contemporánea del derecho internacional parece indicar que si bien los cambios han sido importantes en este plano, o hay otros que se insinúan como tendencias, esos cam-

${ }^{38}$ Francisco Orrego Vicuña y Christopher Pinto, "The peaceful settlement of disputes: prospects for the twenty-first century", Informe elaborado para la 1999 Centennial Commemoration of the First Peace Conference, en Frits Kalshoven (ed.), The Centennial of the First International Peace Conference. Reports and Conclusions, 2000; pp. 261-418.

${ }^{39}$ Allott, op. cit., supra nota 4; p. 167.

${ }^{40}$ Ibid.; p. 168.

${ }^{41}$ Eileen Denza, “Two legal orders: Divergent or Convergent?", International and Comparative Law Quarterly, Vol. 48, 1999, pp. 257-284. 
bios no son lo suficientemente extensos o generalizados como para concluir que el orden jurídico internacional ha variado fundamentalmente de estructura ${ }^{42}$.

La presencia de un proceso evolutivo no significa la ruptura de una estructura fundamental del derecho internacional, pues, tal como ocurre con la propia sociedad internacional, la innovación se combina acertadamente con la estabilidad y la continuidad.

\section{UN PROCESO CONTROLADO DE} LIMITACIÓN DE LA SOBERANÍA

Desde luego, puede observarse que el derecho internacional se caracteriza hoy por un proceso controlado de la limitación de la soberanía. No obstante lo que se sostiene con frecuencia, el Estado nacional no está en vías de desaparecer. Limitaciones de la soberanía sí las ha habido, pero ellas han sido aceptadas por los Estados, ya sea en el marco de las organizaciones internacionales o respecto de los individuos. Este es un proceso controlado por la propia voluntad estatal y se limita en general a algunas materias muy específicas.

El derecho internacional permanece en el tiempo como un derecho que regula las relaciones entre sus sujetos, atendiendo a las particulares características de la sociedad internacional. Ésta es la razón que explica por qué su progreso como orden vertical jerárquico es mucho más li- mitado y excepcional que su expansión horizontal. Por otra parte, ese elemento de jerarquía está presente en el derecho internacional desde sus orígenes, pues no es diferente de los grandes principios ordenadores que fueron derivados del derecho natural o de la existencia de normas fundamentales, todas ellas centradas en la necesidad de proteger los derechos del individuo.

\section{La limitación de la soberanía} es un proceso controlado por la propia voluntad estatal.

En esta perspectiva, no existe en realidad una autoridad que se sitúe por sobre los Estados en la comunidad internacional. Casos puntuales, a no dudarlo, existen, pero todos ellos son organismos internacionales que no tienen más poder legislativo que aquel que le ha sido delegado por los Estados miembros. Esta delegación, aun cuando creciente en los variados campos en que se expresa la cooperación internacional, es siempre controlada y de carácter limitado.

De ahí que la creación de organizaciones internacionales a las que los Estados transfieren algunas de sus competencias, como ocurre en el marco de la Comunidad Europea, sea también verdaderamente excepcional. En esos casos tampoco se trata de una transferencia generalizada que lleve a anular la función del Estado, pues se refiere a materias muy

${ }^{42}$ Rosalyn Higgins, "International Law in a Changing International System", The Cambridge Law Journal, Vol. 58, 1999, pp. 78-95. 
específicas, principalmente de orden comercial.

Incluso en el marco de organismos que se fundamentan en una delegación de ciertas competencias, como es nuevamente el caso de la Comunidad Europea, se aprecia también una política de restricción por parte de los Estados miembros respecto de los poderes que pueden ser ejercidos por esos organismos ${ }^{43}$. La tendencia natural de la administración de esos organismos es la de incrementar sus poderes, frecuentemente por la vía de la interpretación extensiva, materia en la que precisamente los Estados ejercen una mayor vigilancia. Este debate se observa con claridad en la discusión de las alternativas de una Constitución Europea, en que se combinan tendencias federalistas con otras autonomistas, y en definitiva sólo se logra acuerdo respecto de los grandes principios que son comunes a las naciones de ese continente ${ }^{44}$.

\section{El PAPEL DEL ESTADO EN LA ELABORACIÓN DEL DERECHO INTERNACIONAL}

La naturaleza del derecho internacional se aprecia con toda propiedad en lo que respecta a la elaboración y ejecución de sus normas. La elaboración del derecho internacional ha sido y continúa siendo una función principal de los Estados, si bien en alguna medida comparten hoy esa función con las organizaciones inter- nacionales, las que adquieren así un papel complementario. Sólo en una medida muy limitada participan los individuos en este proceso. Los tratados bilaterales y multilaterales son siempre obra de los Estados, los que elaboran así las normas necesarias para lograr sus objetivos.

\section{La influencia de los Estados en la elaboración del derecho internacional depende de su capacidad y poder.}

El grado de influencia que los Estados tienen en este proceso es por cierto diferente, pues depende en buena medida de su capacidad y poder. El marco de las organizaciones internacionales para facilitar la conducción de negociaciones y la agrupación de los Estados con mayor afinidad ha resultado ser eficiente si se le compara con las grandes conferencias gubernamentales del pasado.

Por otra parte, como se ha indicado, la ejecución del derecho internacional descansa en esencia en la cooperación entre los Estados y no cuenta con mecanismos autónomos para este fin. Incluso en materias tan importantes como la prohibición y reglamentación del uso de la fuerza en el marco de las Naciones Unidas, se requiere de la cooperación entre los Estados para que pueda llevarse a cabo. Tampoco ha desaparecido en este contexto el recurso a la doctrina clásica de la legítima defensa ${ }^{45}$.

${ }^{43}$ Denza, loc. cit., supra nota 41; pp. 279-280.

${ }^{44}$ Steven Everts and Daniel Keohane, "The European Convention and E U Foreign Policy: Learning from Failure", Survival, Vol. 45, 2003, pp. 167-186.

${ }^{45}$ Adam Roberts, "Law and the Use of Force After Iraq", Survival, Vol. 45, 2003, pp. 31-56. 
La realidad anterior no impide que mediante mecanismos convencionales se puedan establecer sistemas de ejecución de normas más expeditos, disponiendo incluso de mecanismos de verificación y control. Nuevamente el progreso del derecho internacional es significativo en este plano, pero ello no determina que la estructura del ordenamiento haya cambiado.

\section{La influencia del derecho internacional en los derechos y obligaciones de los individuos exige dotarlo de más transparencia.}

Perfeccionamientos de esta naturaleza se observan de manera creciente en el uso de técnicas legislativas que buscan asegurar que los tratados produzcan sus efectos con mayor celeridad que en el pasado, como también se observan en el desarrollo de un derecho derivado en el marco de algunas organizaciones internacionales con miras a alcanzar una modalidad de aplicación directa que tiene especial expedición. Todo ello, sin embargo, es más bien un problema de técnica legislativa que uno que venga a alterar la naturaleza del sistema del derecho internacional.

Durante un largo período la elaboración y puesta en marcha de las normas del derecho internacional fue el resultado de un proceso de negociación diplomática y, por consiguiente, caracterizado por la privacidad o confidencialidad, cuando no enteramente secreto. Esta realidad se encuentra también en proceso de cambio debido a la intervención más ac- tiva de los parlamentos nacionales y de las propias organizaciones internacionales. En algunas instituciones internacionales se han previsto mecanismos de publicidad e información especialmente diseñados para alcanzar la transparencia del proceso legislativo.

\section{NuEVOS REQUERIMIENTOS}

DE TRANSPARENCIA

Dada la creciente influencia del derecho internacional en los derechos y obligaciones de los individuos, la necesidad de dotarlo de una mayor transparencia se ha hecho evidente. Esta es una necesidad que deberá atenderse satisfactoriamente en la comunidad internacional general, pues también el derecho internacional tiene hoy una fuerte incidencia en las garantías de las democracias nacionales y debe estar sujeto al examen de la ciudadanía.

Esta última razón justifica también la intervención más activa de los parlamentos nacionales en el proceso legislativo internacional, donde igualmente se observan cambios de interés. Originalmente, esa intervención sólo se requería para aprobar lo que el poder ejecutivo ya había negociado en el ámbito internacional. Hoy, en cambio, se observa una participación más activa de los parlamentos mediante su asociación al proceso legislativo internacional. Esta apertura se traduce, aun indirectamente, en una mayor participación ciudadana en el proceso y en una tramitación parlamentaria más expedita de los tratados y otros instrumentos. 
El perfeccionamiento de los métodos legislativos contribuye no sólo a la agilización del proceso de incorporación del derecho internacional al derecho interno, sino que también a una mayor uniformidad en la aplicación de las normas internacionales. Ello ocurre, por ejemplo, mediante la prohibición o la limitación de las reservas a los tratados internacionales. Sin embargo, como consecuencia de la necesidad de una mayor participación ciudadana y de un mayor control democrático sobre la elaboración del derecho internacional, la utilización de las reservas ya no es un privilegio exclusivo del poder ejecutivo sino que requiere, en ocasiones, a lo menos de una consulta parlamentaria. De lo contrario, el alcance de la legislación internacional puede verse alterado por el recurso a las reservas de manera incontrolada.

La aplicación del derecho internacional por los tribunales nacionales también muestra la naturaleza evolutiva del derecho internacional. Como regla general, los tribunales aplicarán las disposiciones de los tratados debidamente ratificados, pero tratándose de normas de costumbre internacional, de principios generales o de arreglos especiales para la aplicación del derecho derivado los individuos pueden invocar directamente las normas del derecho internacional.

Éste es, sin duda, un fenómeno creciente en el marco de la función judicial, pero igualmente requiere de controles estrictos. En ocasiones se ha abusado por la vía de la interpretación antojadiza del derecho internacional de esta facultad jurisdiccional, procurando impulsar desarrollos que no siempre se avienen con la verdadera naturaleza y alcance de la norma internacional en aplicación.

\section{El progreso de los mecanismos de solución de controversias indica una evolución del derecho internacional.}

En consonancia con estos desarrollos, especial importancia tienen los sistemas internacionales de solución de controversias $^{46}$. El progreso de estos mecanismos, con particular referencia al arbitraje, es indicativo de una evolución del propio derecho internacional. Si bien en muchos casos se requiere de la voluntad de los Estados para poner en operación dichos mecanismos, se encuentran disponibles algunas importantes manifestaciones del ejercicio de la jurisdicción obligatoria en campos específicos, como ocurre en el caso de la protección de los derechos del individuo, el comercio internacional y las inversiones. Ello representa el inicio de una tendencia de importancia en el derecho internacional.

El progreso de la jurisdicción penal internacional ha sido otro proceso gradual de importancia ${ }^{47}$. El Estatuto de la Corte Penal Internacional es una expresión de este particular desarrollo. Con todo, este proceso se ha visto en cierta medida afec-

${ }^{46}$ Francisco Orrego Vicuña, International Dispute Settlement in a Global Society, Sir Hersch Lauterpacht Memorial Lectures, 2001, Cambridge University Press, por aparecer.

${ }^{47}$ Antonio Cassese, International Criminal Law, 2003. 
tado por el grado de politización que ha afectado a algunos tribunales internacionales de este tipo y a la negociación que acompañó al Estatuto indicado ${ }^{48}$. Similares dificultades surgen del actuar de algunos tribunales nacionales y de la aprobación de leyes que buscan formas extremas de ejercicio de jurisdicción univer$\mathrm{sal}^{49}$. Todo ello ha sembrado dudas no menores acerca de la viabilidad de un tipo de jurisdicción que no descanse estrictamente en la búsqueda de la justicia y en la observancia escrupulosa de las garantías del debido proceso.

\section{EL DERECHO INTERNACIONAL}

\section{AL SERVICIO DE LOS CIUDADANOS}

Hay todavía otra dimensión que adquiere el derecho internacional en su relación con un derecho interno que es crecientemente el producto de la voluntad libremente expresada en sociedades democráticas. La identificación y perfeccionamiento de los principios y normas del derecho internacional deben realizarse sobre la base de la participación consensual de los Estados, pues sólo así se podrá asegurar que respondan genuinamente a la voluntad democrática de esas sociedades.

La elaboración del derecho internacional mediante la concurrencia de mayorías puede tener utilidad en el caso de regímenes particulares, pero no debe sustituirse el papel del consenso en la comunidad internacional. De lo contrario, se arriesga que el derecho internacional sea el producto de visiones parciales y de mayorías circunstanciales que se utilicen para soslayar la expresión de las sociedades nacionales que difieran de esa visión. La participación consensual en la elaboración del derecho internacional asegura tanto su verdadera universalidad como su sustentación en el tiempo.

\section{La elaboración del derecho internacional por mayorías no debe sustituir el papel del consenso en la comunidad internacional.}

En ocasiones existe la tendencia y el propósito de obtener por la vía de la legislación internacional, especialmente cuando ésta es menos solemne o informal, objetivos que la sociedad nacional no está dispuesta a autorizar en el marco de la operación de sus estructuras democráticas. Este ya se ha transformado en un ejercicio continuado en el marco de conferencias convocadas por Naciones Unidas. Si la concurrencia de voluntades políticas en una sociedad democrática persigue el reconocimiento de ciertos valores y modelos, ellos no pueden verse alterados por el recurso a un orden internacional que no cuenta con el consenso necesario.

${ }^{48}$ Jonathan I. Charney, "Progress in International Criminal Law?", American Journal of International Law, Vol. 93, 1999, pp. 452-464.

${ }^{49}$ Corte Internacional de Justicia, Arrest Warrant of 11 April 2000 (Democratic Republic of Congo v. Belgium), Judgment, ICJ Reports 2002, p. 3. 
Esa modalidad, destinada a soslayar el papel del Estado y su expresión democrática, se traduce también en que por esa vía se procure imponer la visión de algunos países o grupos respecto del orden internacional o la organización de la sociedad nacional al conjunto de la comunidad internacional.

No sólo sería ésta una alternativa ilegítima sino que ella involucra, además, un mal uso del derecho internacional con miras a tergiversar la voluntad ciudadana. En esa medida, el derecho internacional se transforma en un agente de actividad antidemocrática y contradice su propia esencia. El control democrático del proceso de elaboración del derecho internacional, su aplicación e interpretación, son entonces nuevas obligaciones a que debe atender tanto la sociedad nacional como la propia estructura del derecho internacional.

Dada esta compleja interacción normativa es que la codificación y el desarrollo progresivo del derecho internacional deben mantenerse hoy día al nivel de los principios básicos. Este esfuerzo no debe aspirar a resolver por sí los muchos problemas que se encuentran presentes en todos los campos regulados por el derecho, sino únicamente proporcionar un tratamiento común de estas áreas. La tarea de aplicar estos principios a regímenes individuales puede ser entregada a otros mecanismos, especialmente las organizaciones internacionales o los arreglos que los Estados deseen concluir para ese fin.

Todo progreso en el orden internacional está condicionado a que los Estados, y de manera más general la sociedad, lo perciban como útil y complementario de su estructura nacional. No puede existir un progreso genuino y aceptado como legítimo que se fundamente en la imposición de intereses ajenos o en el antagonismo respecto de valores que cada uno se ha dado en el contexto de sus tradiciones históricas y culturales.

Como consecuencia de lo anterior, una constante que puede observarse en la evolución del derecho internacional es que los Estados buscan salvaguardar legítimamente su autonomía. Esta autonomía se ha hecho más relativa en el marco de la transformación del derecho internacional contemporáneo, pero ello ha sido con la aceptación y participación de los propios Estados. Si se busca reducir esta autonomía contra la voluntad estatal, o mediante la creciente utilización de mecanismos subrepticios, lejos de garantizarse un progreso en el derecho internacional se causará una grave regresión.

Mientras el derecho internacional mantenga su naturaleza histórica se asegurará un progreso continuado. Asimismo, ello es una garantía de que los derechos del individuo, destinatarios principales y últimos de todo el ordenamiento jurídico internacional, continuarán siendo salvaguardados mediante una relación de equilibrio provista de controles recíprocos entre el derecho nacional y el derecho internacional. Cada uno de estos sistemas jurídicos tiene la tarea de vigilar que el otro no sobrepase sus límites naturales o tergiverse su funcionamiento en detrimento de los valores permanentes en que se inspiran las sociedades nacionales y la comunidad internacional. 